\title{
Age-Related Trends in the Treatment and Outcomes of Ruptured Cerebral Aneurysms: A Study of the Nationwide Inpatient Sample 2001-2009
}

\author{
W. Brinjikji, G. Lanzino, A.A. Rabinstein, D.F. Kallmes, and H.J. Cloft
}

\begin{abstract}
BACKGROUND AND PURPOSE: Patient age substantially influences treatment decisions for ruptured cerebral aneurysms. It would be useful to understand national age-related trends of treatment techniques and outcomes in patients treated for ruptured cerebral aneurysm in the United States.
\end{abstract}

MATERIALS AND METHODS: Using the US Nationwide Inpatient Sample, we evaluated trends in treatment technique (clipping versus coiling) and discharge status of patients undergoing clipping or coiling of ruptured cerebral aneurysms between 2001 and 2009 . Outcomes were evaluated in relation to 4 age strata: 1) younger than 50 years of age, 2) 50-64 years of age, 3) 65-79 years of age, and 4) patients 80 years or older. We compared outcomes between treatment groups for patients treated between 2001-2004 with those treated between 2005-2009.

RESULTS: A significant increase in the proportion of patients undergoing endovascular coiling between 2001 and 2009 was noted for all age groups $(P<.0001)$. For both clipped and coiled patients, mortality and the proportion of patients discharged to long-term facilities increased with age. Overall mortality for patients clipped and coiled decreased modestly for all age groups, and overall proportions of patients discharged home increased modestly $(P<.01)$ for all age groups except those older than 80 years of age.

CONCLUSIONS: Between 2001 and 2009, there has been a significant increase in the proportion of patients with ruptured aneurysms undergoing endovascular coiling rather than aneurysm clipping. This increase was more pronounced in older patients. Mortality from aneurysmal subarachnoid hemorrhage decreased during the past decade, regardless of aneurysm treatment technique.

ABBREVIATIONS: BRAT = Barrow Ruptured Aneurysm Trial; $\mathrm{CCl}=$ Charlson Comorbidity Index; $\mathrm{Cl}=$ confidence interval; ISAT = International Subarachnoid Aneurysm Trial; NIS = Nationwide Inpatient Sample

$\mathbf{T}$

he International Subarachnoid Aneurysm Trial demonstrated that patients with aneurysmal SAH treated with endovascular coiling had a significantly decreased absolute risk of death or dependency at 1 year compared with patients undergoing surgical clipping. ${ }^{1}$ Because ISAT only randomized patients who were suitable for both coil and clip therapy, just $22 \%$ of patients screened, ${ }^{2}$ the generalizability of these results has been questioned. ${ }^{3}$ Despite this ongoing criticism, subsequent reports indicate that there is a trend toward an increased use of coiling over clipping for patients with aneurysmal SAH. ${ }^{4-8}$ While such a trend toward coiling is undoubtedly occurring, the population of patients treated for $\mathrm{SAH}$ is diverse and subgroups of patients within that popula-

Received March 8, 2012; accepted after revision July 31.

From the Departments of Radiology (W.B., D.F.K., H.J.C.), Neurology (A.A.R.), and Neurosurgery (G.L.), Mayo Clinic, Rochester, Minnesota.

Please address correspondence to Harry J. Cloft, MD, PhD, Mayo Clinic, 200 SW First St, Rochester, MN 55905; e-mail: cloft.harry@mayo.edu

http://dx.doi.org/10.3174/ajnr.A3321 tion will tend to be treated differently, depending on factors such as condition at presentation, aneurysm location, and patient age.

The risk of poor outcome after aneurysmal SAH increases with advancing age, ${ }^{9}$ and a less invasive treatment with endovascular coil embolization rather than clipping has been advocated in the elderly. ${ }^{9-15}$ Although the potential benefits of a less invasive treatment in elderly patients with aneurysmal SAH may seem intuitive, ${ }^{16}$ some series have shown that the risks of endovascular coil embolization in this age group are not negligible, ${ }^{17}$ and 1 singlecenter study demonstrated that the introduction of coil embolization of ruptured aneurysms was not associated with improved outcomes in elderly patients. ${ }^{16}$ However, these studies were limited by the relatively small number of patients available for analysis. To examine the application of this approach in practice in the United States and the effect that this might have on outcomes, we applied the Nationwide Inpatient Sample data from 2001 to 2009 to determine trends with time in treatment technique choice and outcomes across age groups. 


\section{MATERIALS AND METHODS}

We purchased the NIS hospital discharge data base for the period 2001-2009 from the Healthcare Cost and Utilization Project of the Agency for Healthcare Research and Quality, Rockville, Maryland. The NIS is a hospital discharge data base that represents $20 \%$ of all inpatient admissions to nonfederal hospitals in the United States. This data base is the largest publicly available all-payer inpatient care data base with demographic, cost, and outcomes data from nearly 8 million inpatient hospital stays from $>1000$ hospitals. Forty-five states participated in the NIS. ${ }^{18}$

We selected all patients with a diagnosis of subarachnoid hemorrhage (Code 430 in the International Classification of Diseases, Ninth Revision, Clinical Modification [ICD-9-CM]) and an ICD-9-CM procedure code of "clipping of aneurysm" (ICD-9-CM code 39.51) or of "coiling of aneurysm," which included "other repair of aneurysm" (ICD9-CM code 39.52), "endovascular repair or occlusion of head and neck vessels" (ICD-9-CM code 39.72), and "other endovascular repair (of aneurysm) of other vessels” (ICD-9-CM code 39.79). We stratified patients into 4 age groups: 1) patients younger than 50 years of age, 2) patients 50-64 years of age, 3) patients 65-79 years of age, and 4) patients 80 years or older. For each patient, the Charlson Comorbidity Index was calculated to determine the burden of comorbid diseases. ${ }^{19}$ The CCI is predictive of 10-year mortality and is a composite score based on patient comorbidities such as malignancy, cardiovascular disease, respiratory disease, and so forth. Each diagnosis is assigned a score of 1, 2, 3, or 6, depending on how predictive each condition is of mortality. Data such as subarachnoid hemorrhage severity are not included in the CCI. A modified CCI was not applied in this study.

The 2 primary end points of this study were discharge status and in-hospital mortality. For each treatment technique, we assessed outcomes for the period 2001-2009 and also compared outcomes between patients treated between 2001-2004 and 2005-2009. We also determined the proportion of patients in each age group treated with endovascular coiling during the study period (2001-2009).

\section{Statistical Analysis}

Means are presented with their corresponding SDs. $\chi^{2}$ tests were used to compare categoric variables, and a Student $t$ test was used to compare continuous variables. Multivariate logistic regression analysis was used to determine factors that best predicted in-hospital mortality for clipped and coiled patients separately. Variables analyzed included age-group, time period (2001-2004 versus 2005-2009), and CCI. To obtain national estimates, we applied proper weights indicated in the HCUP-NIS Calculating NIS Variances Guide. All statistical analysis was performed by using the SAS-based statistical package JMP (www.jmp.com).

\section{RESULTS}

Between 2001 and 2009, a total of 35,723 patients underwent coiling of ruptured intracranial aneurysms and 53,207 patients underwent clipping of ruptured intracranial aneurysms. Among clipped patients, $21,852(41.1 \%)$ were younger than 50 years of age, $21,189(39.8 \%)$ were $50-64$ years of age, $8844(16.6 \%)$ were 65-79 years of age, and $1322(2.5 \%)$ were 80 years or older. Among coiled patients, $13,382(37.4 \%)$ were younger than 50 years of age, $13,202(37.0 \%)$ were $50-64$ years, $7116(19.9 \%)$ were 65-79 years of age, and 2023 (5.7\%) were 80 years or older.

The proportion of patients undergoing endovascular treatment of ruptured aneurysms increased during the study period in all age groups. In 2001, 8.5\% of patients younger than 50 years of age underwent endovascular coiling compared with $54.7 \%$ in $2009(P<.0001)$. For patients $50-64$ years of age, $6.8 \%$ underwent endovascular coiling in 2001 compared with $55.0 \%$ in 2009 $(P<.0001)$. For patients $65-79$ years, $7.8 \%$ underwent endovascular coiling in 2001 compared with $60.4 \%$ in 2009 . For patients 80 years or older, $22.3 \%$ underwent endovascular coiling in 2001 compared with $69.1 \%$ in $2009(P<.0001)$. For each year, increasing age was associated with an increased proportion of patients undergoing endovascular coiling (Fig 1).

Outcomes for 2001-2009 are summarized in Table 1. For clipped patients, increasing age predicted a decreased proportion of patients being discharged home and an increased proportion of patients being discharged to long-term facilities or suffering inhospital mortality. The mean length of stay increased significantly with increasing age group as did the non-age-corrected Charlson Comorbidity Index. The same was true for patients undergoing endovascular coiling.

When comparing outcomes for all patients (treated with either clipping or coiling), we found significant differences between the 2 time periods. These data are summarized in Fig 2. For all age groups, mortality significantly decreased in 2005-2009 compared with 2001-2004. For patients younger than age 80 years, there was 
Table 1: Outcomes of all patients with coiled and clipped SAHs by age in years: 2001-2009

\begin{tabular}{|c|c|c|c|c|c|c|c|c|}
\hline \multirow[b]{2}{*}{ Discharge Status } & \multicolumn{4}{|c|}{ Clipped } & \multicolumn{4}{|c|}{ Coiled } \\
\hline & $\begin{array}{l}\text { Younger } \\
\text { than } 50\end{array}$ & $50-64$ & $65-79$ & 80 or Older & $\begin{array}{l}\text { Younger } \\
\text { than } 50\end{array}$ & $50-64$ & $65-79$ & 80 or Older \\
\hline Home (No.) (\%) & $13125(60.1)$ & $9142(43.1)^{a}$ & $1894(21.4)^{a}$ & $102(7.7)^{\mathrm{a}}$ & $8306(62.1)$ & $6388(48.4)^{a}$ & $1862(26.2)^{\mathrm{a}}$ & $246(12.2)^{\mathrm{a}}$ \\
\hline Short-term facility (No.) (\%) & $690(3.2)$ & $816(3.9)$ & $383(4.3)$ & $41(3.1)$ & $505(3.8)$ & $506(3.8)$ & $292(4.1)$ & $92(4.5)^{a}$ \\
\hline Long-term facility (No.) (\%) & $5895(27.0)$ & $8546(40.3)^{a}$ & $4936(55.8)^{\mathrm{a}}$ & $832(62.9)^{a}$ & $3226(24.1)$ & $4418(33.5)^{\mathrm{a}}$ & $3510(49.3)^{\mathrm{a}}$ & $1057(52.3)^{\mathrm{a}}$ \\
\hline In-hospital death (No.) (\%) & $2021(9.3)$ & $2650(12.5)^{\mathrm{a}}$ & $1596(18.0)^{\mathrm{a}}$ & $342(25.8)^{\mathrm{a}}$ & $1306(9.8)$ & $1843(14.0)^{\mathrm{a}}$ & $1432(20.1)^{\mathrm{a}}$ & $608(30.1)^{a}$ \\
\hline Mean LOS (SD) & $19.0(32.2)$ & $21.5(37.4)^{\mathrm{a}}$ & $24.2(35.3)^{a}$ & $24.2(32.7)^{\mathrm{a}}$ & $18.1(31.6)$ & $19.2(30.1)^{\mathrm{a}}$ & $20.7(30.2)^{\mathrm{a}}$ & $19.7(28.5)^{\mathrm{a}}$ \\
\hline Mean CCI (SD) & $1.2(1.3)$ & $1.4(1.5)^{\mathrm{a}}$ & $1.5(1.8)^{a}$ & $1.6(1.9)^{a}$ & $1.3(1.7)$ & $1.5(1.8)^{a}$ & $1.6(1.9)^{\mathrm{a}}$ & $1.7(1.9)^{\mathrm{a}}$ \\
\hline
\end{tabular}

Note:-LOS indicates length of stay.

a $P<.0001$ compared with the $<50$ group.

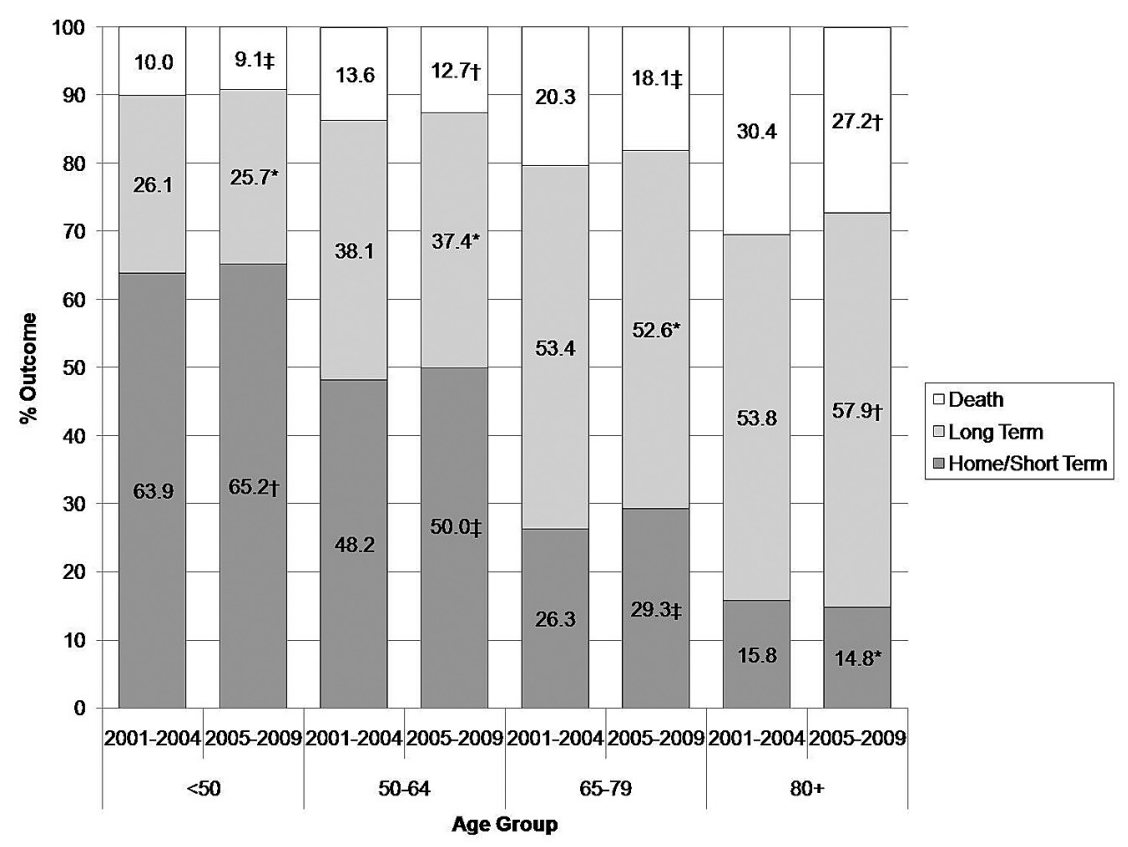

FIG 2. Outcomes for all treated patients with SAH, 2001-2004 versus 2005-2009. Asterisk indicates $P=$ not significant; dagger, $P<.05$; double dagger, $P<.01$. with patients treated in 2001-2004 (50.1\% compared with $46.9 \%, P=.02$ ). For patients 80 years or older, $37.8 \%$ had in-hospital mortality in 2001-2004 compared with $27.0 \%$ in $2005-2009$ ( $P$ < .0001). Significantly more patients were discharged to long-term facilities in 2005-2009 compared with 2001-2004 (56.1\% compared with $42.4 \%$ respectively, $P<.0001)$.

When performing multivariate logistic regression analysis (Table 2), we found that for both clipped and coiled patients, increasing age and increasing CCI were predictive of increased mortality. For clipped patients, the odds of mortality in 2005-2009 was 0.87 (95\% CI, 0.83-0.92) compared with patients treated in 20012004. For coiled patients, the odds of mortality for patients treated in 20052009 was 0.79 (95\% CI, 0.74-0.84) compared with those patients treated in 2001-2004. a significant increase in patients discharged to home and shortterm facilities.

Outcomes of clipped patients during the study period are summarized in Fig 3. For clipped patients younger than 50 years of age, the mortality rate in 2001-2004 was 9.9\% compared with $8.6 \%$ in $2005-2009(P<.0001)$. In $2001-2004,63.1 \%$ of patients younger than 50 years of age were discharged to home or shortterm facilities compared with $64.6 \%$ in $2005-2009(P=.02)$. For patients $50-64$ years of age, $13.1 \%$ had in-hospital mortality in 2001-2004 compared with $11.9 \%$ in 2005-2009 ( $P=.005)$. No significant differences were found in outcomes of clipped patients 65 years of age and older between the 2 time periods.

Outcomes of coiled patients during the study period are summarized in Fig 4. For coiled patients, no significant differences in discharge status were found for patients younger than 50 years of age between the 2 time periods. For patients 50-64 years of age, mortality in 2001-2004 was $15.3 \%$ compared with $13.5 \%$ in 2005-2009 $(P=.01)$. For patients 65-79 years of age, the mortality rate was $24.4 \%$ in the earlier time period compared with $18.7 \%$ in the later one $(P<.0001)$. However, significantly more patients were discharged to long-term facilities in 2005-2009 compared

\section{DISCUSSION}

Our study demonstrates that between 2001 and 2009, there has been a substantial increase in the proportion of patients with ruptured aneurysms undergoing endovascular coiling. This increase is more prominent among older patients. The relative strengths and weaknesses of clipping and coiling have been shifting with time, and treating physicians incorporate their understanding of the state-of-the-art for these procedures into their clinical decision-making process. It seems that despite public debate and controversy over the results of the ISAT trial, ${ }^{20,21}$ patients are increasingly being referred for endovascular therapy. However, while coiling has become the procedure of choice for most patients, clipping is still being offered to a substantial number of patients, especially those who are younger. The lower use of coiling in younger patients is supported by the ISAT results, which showed little difference in outcomes for clipping and coiling for patients 40 years old and younger, ${ }^{22}$ and by the better durability of surgical clipping.

The NIS data base is quite different from a randomized study. It includes all patients treated with clipping and coiling and is, therefore, affected by biases related to choice of treatment. It is not 


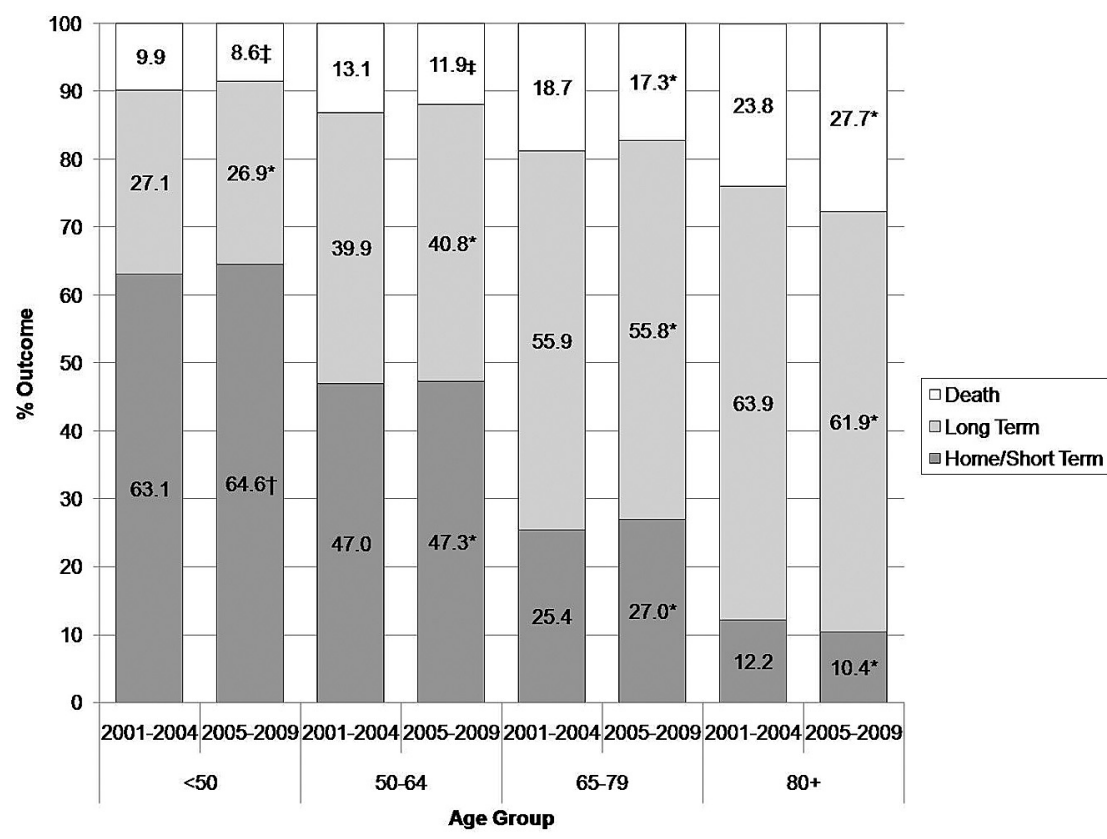

FIG 3. Outcomes for patients with clipped SAH, 2001-2004 versus 2005-2009. Asterisk indicates $P=$ not significant; dagger, $P<.05$; double dagger, $P<.01$.

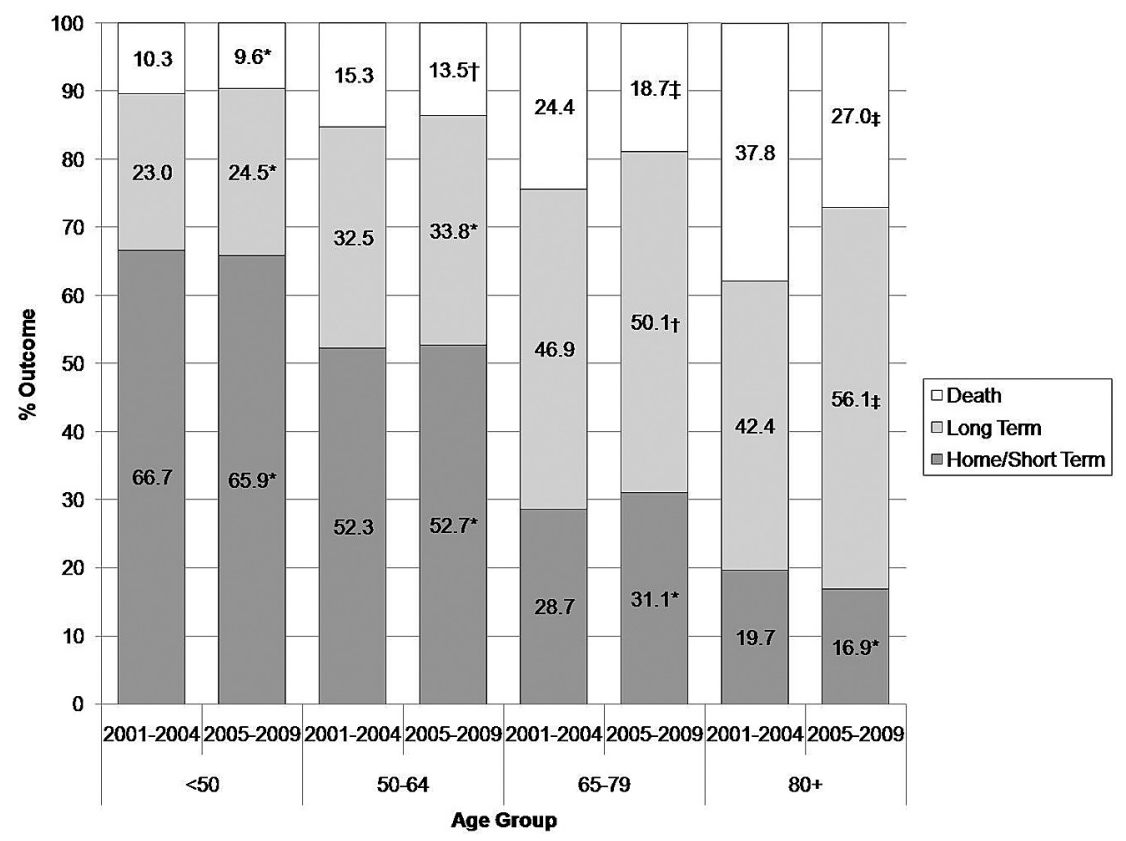

FIG 4. Outcomes for patients with coiled SAH, 2001-2004 versus 2005-2009. Asterisk indicates $P=$ not significant; dagger, $P<.05$; double dagger, $P<.01$.

possible to know, from the NIS, the condition of patients at presentation, but it is quite likely that patients in worse clinical condition tended to be directed toward endovascular therapy. The distribution of aneurysm location would be expected to be quite different in the clipping and coiling groups (eg, more basilar aneurysms in the coiling group and more middle cerebral artery aneurysms in the clipping group). Also, the less invasive nature of coiling relative to clipping has resulted in aneurysm treatment for patients of poor clinical grade who would not have been offered surgery. Because of these issues, the NIS should not be used for direct comparisons of outcomes of clipping and coiling of ruptured aneurysms but rather to study the practice patterns and outcomes with time for all patients undergoing treatment for ruptured aneurysm in the United States. The results of our NIS study show that outcomes for patients treated with either clipping or coiling for ruptured aneurysm in the United States have improved in 2005-2009 compared with 2001-2004 for all age groups. It is reasonable to speculate that this improvement is explained, at least in part, by a more individualized and judicious selection of aneurysm treatment technique with time. One other major variable that may factor into improved outcomes among clipped and coiled patients is improvement in the neurocritical care these patients receive.

O'Kelly et $\mathrm{al}^{6}$ compared surgical clipping and endovascular coiling of ruptured intracranial aneurysms in a Canadian population of patients with $\mathrm{SAH}$ treated between 1995 and 2004 and concluded that coiling increased the hazard of death and subsequent readmission for $\mathrm{SAH}$ (hazard ratio, 1.25 [95\% CI, 1.00-1.55]; $P=.04)$ and called into question the generalizability of the ISAT results. During the study period, the proportion of aneurysms treated by endovascular coiling increased from $17 \%$ to $41 \% .^{6}$ This Canadian study was performed at an earlier stage in the development of endovascular therapy, which perhaps helps explain the worse outcomes with coiling. It is quite possible that, especially at the beginning of coil use, primarily patients considered to be poor candidates for surgery were treated with coil embolization.

Other studies have suggested that incorporation of the ISAT results into practice has improved the outcome of aneurysmal SAH. Qureshi et $\mathrm{al}^{5}$ showed that the in-hospital mortality in the United States after admission for spontaneous subarachnoid hemorrhage decreased from $27 \%$ to $24 \%$ ( $P=$ $.003)$ as the fraction of coiled-versus-clipped cases increased from $8 \%$ to $43 \%$ in the 3 years after the publication of the ISAT relative to the 3 years prior. Following publication of the ISAT study, concerns existed about the generalizability of the outcome observed in the study to the United States, where there is a higher degree of subspecialization among neurosurgeons involved in the care of patients with aneurysmal SAH. The Barrow Ruptured Aneurysm Trial, a randomized trial of clipping versus coiling, offers 
Table 2: Multivariate results of predictors of mortality

\begin{tabular}{|c|c|c|c|c|}
\hline & \multicolumn{2}{|c|}{ Clipped Patients } & \multicolumn{2}{|c|}{ Coiled Patients } \\
\hline & OR (95\% Cl) & $P$ & OR (95\% Cl) & $P$ \\
\hline \multicolumn{5}{|l|}{ Age group (yr) } \\
\hline Younger than 50 & Ref & Ref & Ref & Ref \\
\hline $50-64$ & $1.36(1.28-1.44)$ & $<.0001$ & $1.46(1.35-1.57)$ & $<.0001$ \\
\hline $65-79$ & $2.02(1.88-2.17)$ & $<.0001$ & $2.20(2.02-2.38)$ & $<.0001$ \\
\hline 80 or older & $3.19(2.79-3.64)$ & $<.0001$ & $3.67(3.28-4.11)$ & $<.0001$ \\
\hline \multicolumn{5}{|l|}{ Time period } \\
\hline 2001-2004 & Ref & Ref & Ref & Ref \\
\hline 2005-2009 & $0.87(0.83-0.92)$ & $<.0001$ & $0.79(0.74-0.84)$ & $<.0001$ \\
\hline $\mathrm{CCl}$ & $1.23(1.19-1.27)$ & $<.0001$ & $1.22(1.18-1.26)$ & $<.0001$ \\
\hline
\end{tabular}

perhaps the most compelling confirmatory evidence to support a shift toward endovascular therapy following ISAT. ${ }^{23}$ Poor outcome was observed in $33.7 \%$ of the patients assigned to clipping and in $23.2 \%$ of the patients assigned to coiling (odds ratio, 1.68; $95 \% \mathrm{CI}, 1.08-2.61 ; P=.02)$. If BRAT patients who entered the study with a Hunt and Hess grade of I or II are considered separately, poor outcomes were associated with $9.4 \%$ of patients treated with endovascular therapy and $19.8 \%$ of patients treated with surgical clipping.. A policy of intent-to-treat favoring coil embolization resulted in fewer poor outcomes than clip occlusion at 1 year following treatment. Although most aneurysms assigned to the coil treatment group in BRAT were treated by coil embolization, a substantial number crossed over to surgical clipping; this finding indicates that surgery is still an important therapeutic option in many patients. ${ }^{23}$

The durability of coil embolization is a concern because the ISAT study has demonstrated a small but real risk of delayed rupture of the target aneurysm, and this risk is higher with coiling than with surgical clipping. However, this small risk of delayed rupture (approximately $0.3 \%$ /year) did not negate the benefit seen after coiling during the first year. ${ }^{24}$ It is possible that the durability of coiled aneurysms may have improved with better technology, increased operator experience, and better judgment of which aneurysms to treat. In BRAT, no delayed ruptures were reported in the endovascular arm after 2 years. ${ }^{23}$

Outcomes for patients treated with clipping during 2001-2004 were quite similar to those of patients treated with coiling during 2005-2009, suggesting that there were no major changes in practice that improved outcomes from clipping for patients age 65 years and older. However, mortality among coiled patients 65 of age and older declined between the 2 time periods. A decrease in mortality in patients treated with endovascular therapy might be due to improvements in techniques but likely reflects the increasing use of endovascular therapy in patients with less severe presentations during the latter period. Because the NIS does not allow determination of a patient's condition at presentation, we cannot confirm this with certainty.

Our results show only $15 \%$ of patients 80 years and older and $29 \%$ of patients age $65-79$ years who underwent clipping or coiling from 2005 to 2009 following a subarachnoid hemorrhage were discharged to home or a short-term care facility. There are many other reports of outcomes for elderly patients with ruptured aneurysms reported in the literature, but the discharge status in the NIS is not precisely comparable with those other studies, which typically report the Glasgow Outcome Scale or the modified
Rankin Scale. In the International Cooperative Study on the Timing of Aneurysm Surgery conducted between 1980 and 1983, 45\% of patients 70 years or older who were surgically treated were independent on the basis of the Glasgow Outcome Scale at 6 months. ${ }^{25}$ Results from a multicenter North American study conducted from 1989 to 1991 (ie, also before coiling was a treatment option) showed that $37 \%$ of those 70 years and older were independent at 3 months on the basis of the Glasgow Outcome Scale, and outcome was highly dependent on condition at presentation. ${ }^{26}$ The outcomes in single-center series were highly dependent on condition at presentation, with Hunt and Hess grades 1 and 2 leading to good outcomes in 57\%-94\%, and Hunt and Hess grades 4 and 5 leading to favorable outcome in $0 \%-16 \% .^{9-13,15}$ It is impossible to know the condition at presentation of the patients in the NIS, but it is quite likely that many of the bad outcomes in the NIS patients were due to the severity of the initial hemorrhage.

A subgroup analysis of patients 65 years and older enrolled in ISAT showed that $60.1 \%$ of patients allocated to coiling were independent compared with $56 \%$ allocated to clipping $(P=.47) .{ }^{17}$ These outcomes are significantly better than those in the NIS, probably because $83 \%$ of the patients in ISAT were World Federation of Neurosurgical Societies grade 1 or $2 .{ }^{17}$ In patients with internal carotid artery or posterior communicating artery aneurysms, $72 \%$ of patients undergoing endovascular therapy were independent compared with only $52 \%$ undergoing clipping $(P<$ $.05)$. However, the reverse was true for middle cerebral artery aneurysms, with good outcome occurring in $46 \%$ of patients treated with coiling and in $87 \%$ of patients treated with clipping $(P<.05)$. This demonstrates that in addition to age, aneurysm location is a critical factor to consider in the choice of therapy.

An overly aggressive approach to coil embolization could result in a higher complication rate that might offset the benefits of endovascular therapy demonstrated in ISAT and BRAT. It therefore remains important that high-quality surgical clipping be available as a treatment technique for ruptured cerebral aneurysms. Ideally, ruptured intracranial aneurysms should be treated in large-volume centers with extensive expertise in both open surgical and endovascular techniques and where treatment decisions are made by consensus after careful evaluation of each case. ${ }^{27}$ The proportions of ruptured aneurysms treated with coiling versus clipping for all age groups with time appear to have reached a plateau, indicating that a relative equilibrium was reached. This equilibrium between clipping and coiling will vary somewhat from center to center depending on local expertise and patient referral patterns. As we learn more in the future about the relative strengths of clipping and coiling for specific patients and specific aneurysms, the balance may shift again.

In addition to the limitations already mentioned, coding inaccuracies can affect the accuracy of any administrative data base. This data base does not offer any data on the severity of SAH on presentation and aneurysm geometric features (aspect and dometo-neck ratio), size, or location. We were unable to assess the effects of improved neurocritical care on outcomes for patients in this study. Information on long-term outcomes is not available from the NIS, and it is well-known that patients with aneurysmal subarachnoid hemorrhage can improve considerably after discharge. We do not have information on recurrent bleeding. How- 
ever, the experiences of ISAT, ${ }^{24}$ the Cerebral Aneurysm Rerupture After Treatment ${ }^{28}$ study, and the BRAT study suggest that it is quite unlikely that the initial treatment benefit of endovascular coil embolization could be overwhelmed by delayed hemorrhages or complications related to retreatment.

\section{CONCLUSIONS}

Between 2001 and 2009, there has been a significant increase in the proportion of patients with ruptured aneurysm undergoing endovascular coiling, which was more pronounced in older patients. Mortality from aneurysmal subarachnoid hemorrhage decreased during the past decade, regardless of aneurysm treatment technique.

Disclosures: Giuseppe Lanzino-UNRELATED: Expert Testimony: ev3, Comments: FDA panel presentation, Other: ev3, ${ }^{*}$ Synthes, ${ }^{*}$ Comments: educational grants. Alejandro A. Rabinstein-UNRELATED: Consultancy: Boerhinger Ingelheim, Comments: advisory board, single meeting, Grants/Grants Pending: CardioNet;* Royalties: Elsevier, Comments: authored and edited books, Other: Boston Scientific, Comments: payment for work as Safety Monitor for clinical trial. David F. KallmesUNRELATED: Grants/Grants Pending: ev3,* MicroVention,* Codman,* Sequent Medical,* Benvenue Medical, ${ }^{*}$ Royalties: University of Virginia Patent Foundation, Payment for Development of Educational Presentations: ev3, ${ }^{*}$ CareFusion, ${ }^{*}$ Travel/ Accommodations/Meeting Expenses Unrelated to Activities Listed: MicroVention.* Harry J. Cloft-UNRELATED: Grants/Grants Pending: Cordis Endovascular. * *Money paid to the institution.

\section{REFERENCES}

1. Molyneux AJ, Kerr RS, Yu LM, et al. International Subarachnoid Aneurysm Trial (ISAT) of neurosurgical clipping versus endovascular coiling in 2143 patients with ruptured intracranial aneurysms: a randomised comparison of effects on survival, dependency, seizures, rebleeding, subgroups, and aneurysm occlusion. Lancet 2005;366:809-17

2. Molyneux A, Kerr R, Stratton I, et al. International Subarachnoid Aneurysm Trial (ISAT) of neurosurgical clipping versus endovascular coiling in 2143 patients with ruptured intracranial aneurysms: a randomised trial. Lancet 2002;360:1267-74

3. Nichols DA, Brown RD Jr, Meyer FB. Coils or clips in subarachnoid haemorrhage? Lancet 2002;360:1262-63

4. Klompenhouwer EG, Dings JT, van Oostenbrugge RJ, et al. Singlecenter experience of surgical and endovascular treatment of ruptured intracranial aneurysms. AJNR Am J Neuroradiol 2011;32: 570-75

5. Qureshi AI, Vazquez G, Tariq N, et al. Impact of International Subarachnoid Aneurysm Trial results on treatment of ruptured intracranial aneurysms in the United States: clinical article. J Neurosurg 2011;114:834-41

6. O'Kelly CJ, Kulkarni AV, Austin PC, et al. The impact of therapeutic modality on outcomes following repair of ruptured intracranial aneurysms: an administrative data analysis: clinical article. $J \mathrm{Neu}$ rosurg 2010;113:795-801

7. Gnanalingham KK, Apostolopoulos V, Barazi S, et al. The impact of the International Subarachnoid Aneurysm Trial (ISAT) on the management of aneurysmal subarachnoid haemorrhage in a neurosurgical unit in the UK. Clin Neurol Neurosurg 2006;108:117-23

8. Cognard C, Pierot L, Anxionnat R, et al. Results of embolization used as the first treatment choice in a consecutive nonselected population of ruptured aneurysms: clinical results of the Clarity GDC study. Neurosurgery 2011;69:837-41, discussion 42

9. Sedat J, Dib M, Lonjon M, et al. Endovascular treatment of ruptured intracranial aneurysms in patients aged 65 years and older: follow-up of 52 patients after 1 year. Stroke 2002;33:2620-25

10. Lubicz B, Leclerc X, Gauvrit JY, et al. Endovascular treatment of ruptured intracranial aneurysms in elderly people. AJNR Am J Neuroradiol 2004;25:592-95

11. Johansson M, Norback O, Gal G, et al. Clinical outcome after endovascular coil embolization in elderly patients with subarachnoid hemorrhage. Neuroradiology 2004;46:385-91

12. Cai Y, Spelle L, Wang H, et al. Endovascular treatment of intracranial aneurysms in the elderly: single-center experience in 63 consecutive patients. Neurosurgery 2005;57:1096-102, discussion 102

13. Bradac GB, Bergui M, Fontanella M. Endovascular treatment of cerebral aneurysms in elderly patients. Neuroradiology 2005;47: 938-41

14. Proust F, Gerardin E, Derrey S, et al. Interdisciplinary treatment of ruptured cerebral aneurysms in elderly patients. J Neurosurg 2010; 112:1200-07

15. Jain R, Deveikis J, Thompson BG. Endovascular management of poor-grade aneurysmal subarachnoid hemorrhage in the geriatric population. AJNR Am J Neuroradiol 2004;25:596-600

16. Karamanakos PN, Koivisto T, Vanninen R, et al. The impact of endovascular management on the outcome of aneurysmal subarachnoid hemorrhage in the elderly in eastern Finland. Acta Neurochir (Wien) 2010;152:1493-502

17. Ryttlefors M, Enblad P, Kerr RS, et al. International Subarachnoid Aneurysm Trial of neurosurgical clipping versus endovascular coiling: subgroup analysis of $\mathbf{2 7 8}$ elderly patients. Stroke 2008;39: $2720-26$

18. HCUP Nationwide Inpatient Sample (NIS) 2001-2009. Rockville, Maryland. http://www.hcup-us.ahrq.gov/nisoverview.jsp. Accessed July 30, 2012

19. Charlson ME, Pompei P, Ales KL, et al. A new method of classifying prognostic comorbidity in longitudinal studies: development and validation. J Chronic Dis 1987;40:373-83

20. Raper DM, Allan R. International Subarachnoid Trial in the long run: critical evaluation of the long-term follow-up data from the ISAT trial of clipping vs coiling for ruptured intracranial aneurysms. Neurosurgery 2010;66:1166-69, discussion 69

21. Bakker NA, Metzemaekers JD, Groen RJ, et al. International SubArachnoid Aneurysm Trial 2009: endovascular coiling of ruptured intracranial aneurysms has no significant advantage over neurosurgical clipping. Neurosurgery 2010;66:961-62

22. Mitchell P, Kerr R, Mendelow AD, et al. Could late rebleeding overturn the superiority of cranial aneurysm coil embolization over clip ligation seen in the International Subarachnoid Aneurysm Trial? J Neurosurg 2008; 108:437-42

23. McDougall CG, Spetzler RF, Zabramski JM, et al. The Barrow Ruptured Aneurysm Trial. J Neurosurg 2012;116:135-44

24. Molyneux AJ, Kerr RS, Birks J, et al. Risk of recurrent subarachnoid haemorrhage, death, or dependence and standardised mortality ratios after clipping or coiling of an intracranial aneurysm in the International Subarachnoid Aneurysm Trial (ISAT): long-term follow-up. Lancet Neurol 2009;8:427-33

25. Kassell NF, Torner JC, Haley EC Jr, et al. The International Cooperative Study on the Timing of Aneurysm Surgery. Part 1. Overall management results. J Neurosurg 1990;73:18-36

26. Lanzino G, Kassell NF, Germanson TP, et al. Age and outcome after aneurysmal subarachnoid hemorrhage: why do older patients fare worse? J Neurosurg 1996;85:410-18

27. Leake CB, Brinjikji W, Kallmes DF, et al. Increasing treatment of ruptured cerebral aneurysms at high-volume centers in the United States. J Neurosurg 2011;115:1179-83

28. CARAT Investigators. Rates of delayed rebleeding from intracranial aneurysms are low after surgical and endovascular treatment. Stroke 2006;37:1437-42 